\title{
CASSCF and MRSDCI Calculations on the Low Energy States of Manganese Mononitride
}

\author{
Marcos H. Oliveira, Marcelo A. P. Pontes, Harley P. M. Filho, Joaquim \\ D. M. Neto \& Francisco B. C. Machado
}

Entre as diatômicas contendo metais de transição associado a um elemento do grupo principal, o mononitreto de manganês tem apenas alguns dados espectroscópicos publicados. Nós estudamos os estados de mais baixa energia do MnN usando cálculos ab initio MRSDCI. Para cada um dos estados ${ }^{1,3,5} \Sigma^{-},{ }^{1,3,5} \Pi$ e $^{1,3,5} \Delta$, a função de onda de referência foi obtida em nível CASSCF. Curvas de energia potencial são apresentadas para estados de mais baixa energia. Constantes espectroscópicas foram determinados com o nosso código, assumindo uma função potencial do tipo Morse. Para o estado fundamental ${ }^{3} \Sigma$, as constantes espectroscópicas calculadas são: $\mathrm{R}_{\mathrm{e}}=1.582 \AA ⿻ \omega_{\mathrm{e}}=808 \mathrm{~cm}^{-1}$ $\mathrm{e}_{\mathrm{e}}=0.69 \mathrm{eV}$.

Palavras-chave: mononitreto de manganês, constantes espectroscópicas, multireferência (MR).

Among the diatomics containing transition metal and a main group element, manganese mononitride has only a few undisputed spectroscopic data published. In this work we study the low lying states of MnN using ab initio MRSDCI calculations. For each one of the ${ }^{1,3,5} \Sigma^{-}, 1,3,5 \Pi$, and ${ }^{1,3,5} \Delta$ states the reference wavefunction has been obtained at the CASSCF level. Potential energy curves are presented for low lying states. Spectroscopic constants have been determined assuming a Morse-type potential function using our code. For the ground ${ }^{3} \Sigma^{-}$state, the calculated spectroscopic constants are $\mathrm{R}_{\mathrm{e}}=1.582 \AA, \omega_{\mathrm{e}}=808 \mathrm{~cm}^{-1}$ and $\mathrm{D}_{\mathrm{e}}=0.69 \mathrm{eV}$.

Keywords: manganese mononitride, spectroscopic constants, multireference (MR). 


\section{Introduction}

In the last decade several research groups have turned their attention to diatomic molecules containing transition metals bonded to main group elements. This interest focus in the theoretical description and interpretation of the exceedingly complicated spectra of such species ${ }^{1}$, what involves the determination of the spectroscopic constants and correct identification of their lowest energy states. Such molecules are very important for Astrophysics, modeling of heterogeneous catalysis and even in the study of mechanisms of biological nitrogen fixation ${ }^{1,2}$. In spite of this growing interest, the properties of several species still remain undetermined, either theoretically or experimentally. Manganese mononitride $(\mathrm{MnN})$ is one such species. Miao and Lambrecht ${ }^{3}$ have analyzed the structure and magnetic properties of $\mathrm{MnN}$. They have used density functional theory (DFT) with a complete linear potential of muffin-tin orbitals in different phases. They have suggested that the equilibrium distance for $\mathrm{MnN}$ should be $1.59 \AA$. Sahu and Kleinman ${ }^{4}$ have examined the density of states for solid $\mathrm{MnN}$ in its tetragonally distorted structure. Andrews, Bare and Chertihin ${ }^{5}$ have codeposited $\mathrm{Mn}$ atoms obtained through a laser ablated reaction in a inert solid $\mathrm{Ar}$ atmosphere, attributing a $916 \mathrm{~cm}^{-1}$ band to the $\mathrm{Mn}^{14} \mathrm{~N}$ species and have interpreted their results using DFT. $\mathrm{Wu}^{6}$ assumed that the $5 \Pi$ is the ground state, in agreement with Andrews and coworkers 5 . Finally, by Harrison ${ }^{2}$ has listed the main candidates to ground state as ${ }^{1,3,5} \Sigma^{-},{ }^{3} \Delta$ and $5 \Pi$. Based on the aforementioned references, and given the many possibilities arising from different couplings as pointed out by Harrison ${ }^{2}$, the available results for the $\mathrm{MnN}$ species cannot be considered conclusive and the question about its ground state remains open. Therefore, we decided to investigate this system using quantum mechanical calculations on the most likely candidates to ground state.

\section{Computational Details}

For the description of this molecule we have followed the same protocol as in our previous work on $\mathrm{FeN}^{7}$, which is itself very similar to the one used by Borin ${ }^{8}$ for NiC. For manganese we have chosen the $(14 \mathrm{~s}, 9 \mathrm{p}, 5 \mathrm{~d})$ Gaussian basis set of Wachter ${ }^{9}$ augmented with $2 \mathrm{p}, 1 \mathrm{~d}$ and $3 \mathrm{f}$ functions according to Bauschlicher ${ }^{10}$. This basis set after the contraction may be represented as $(14 s, 11 p, 6 d, 3 f) /[8 s, 6 p, 4 d, 1 f]$. For the nitrogen atom we have used the correlation-consistent polarized valence triple- $\zeta$ (cc-pVTZ) set developed by Dunning and Woon $^{11-12}$. Following references ${ }^{2-6}$, we have examined the ${ }^{1,3,5} \Sigma^{-},{ }^{1,3,5} \Pi$, and ${ }^{1,3,5} \Delta$ states. These states belong to the irreducible representations $\mathrm{A}_{1}\left(\Sigma^{+}, \Delta\right), \mathrm{B}_{1,2}(\Pi)$ and $\mathrm{A}_{2}($ $\Sigma^{-}, \Delta$ ) within the $\mathrm{C}_{2 \mathrm{v}}$ point group. It is well known that diatomic molecules containing a first row transition metal and a main group element undergo severe correlation effects. Accordingly, one must consider those effects due to differential occupation of the $\mathrm{d}$ shell (in this case, $3 \mathrm{~d}^{6} 4 \mathrm{~s}^{1}$ relative to $\left.3 d^{5} 4 s^{2}\right)^{7,8,13}$. In this work we have obtained the zero order wavefunction using the complete active space self-consistent field (CASSCF) method ${ }^{14-18}$. For the CASSCF calculations, all core orbitals (1s, 2s, 2p, 3s and $3 p$ of the metal atom plus $1 \mathrm{~s}$ of the main group element) were kept doubly occupied. The active space spanned the $4 \mathrm{~s}$ and $3 \mathrm{~d}$ orbitals of manganese and $2 \mathrm{~s}$ and $2 \mathrm{p}$ of nitrogen. In a later step, the dynamic correlation was evaluated with multireference singles and doubles configuration interaction (MRSDCI) calculations ${ }^{19}$. The MRSDCI step increased the active space to 14 orbitals. In addition, we have included relativistic corrections as suggested by Douglas and $\mathrm{Kroll}^{20}$. In all calculations, we have used the GAMESS $\operatorname{code}^{21}$. The evaluation of spectroscopic constants was carried out using a worksheet written by one of us within the MathCad platform. The reported constants are all based in a Morse potential curve ${ }^{22}$.

\section{Results and Discussion}

The CASSCF level indicates the ${ }^{5} \Delta$ as the ground state, there is a number of close states following: ${ }^{5} \Pi<^{3} \Sigma^{-}$, all within a $2.2 \mathrm{eV}$ energy span. We recall that so far ${ }^{5} \Pi$ has been regarded as the ground state, with the ${ }^{3} \Sigma^{-}$very close to it, in agreement to a previous suggestion by $\mathrm{Wu}^{6}$ and Andrews ${ }^{5}$. Among these two, we have estimated the ${ }^{5} \Pi$ to be the lowest state by only $2.4 \mathrm{kcal}^{\mathrm{mol}}{ }^{-1}$, what compares to Andrews' value of $0.8 \mathrm{kcal}^{\mathrm{mol}}{ }^{-1}$. The zeroth order wavefunctions for both states have marked multiconfigurational character, as they may be represented by:

$$
\begin{gathered}
{ }^{5} \Pi \approx 0,642 \mid(3 \pi)^{4}(1 \delta)^{2}(4 \pi)^{1}(10 \sigma)^{1}>+\ldots \text { and } \\
{ }^{3} \Sigma^{-} \approx 0,725 \mid(3 \pi)^{4}(1 \delta)^{2}(4 \pi)^{0}(10 \sigma)^{0}>+\ldots
\end{gathered}
$$


The inclusion of four orbitals in the active space for the MRSDCI step brings upon a shuffle in the MO ordering, as the ${ }^{3} \Sigma^{-}$state is now the lowest lying (by 2.5 kcal.mol ${ }^{-1}$ ) followed by ${ }^{5} \Pi<{ }^{3} \Pi<{ }^{5} \Delta$, this order is presented in the Figure 1. The composition of the wavefunctions at this level remains multiconfigurational:

$$
\begin{gathered}
{ }^{5} \Pi \approx 0,704 \mid(3 \pi)^{4}(1 \delta)^{2}(9 \sigma)^{1}(4 \pi)^{1}>+\ldots \text { and } \\
{ }^{3} \Sigma^{-} \approx 0,766 \mid(3 \pi)^{4}(1 \delta)^{2}(9 \sigma)^{2}(4 \pi)^{0}>+\ldots
\end{gathered}
$$

It is not clear how to compare these results with previous ones, since no details were given in the previous works ${ }^{5,6}$ on how the energy difference was obtained. On the other hand, it is conceivable that a MR-SDCI calculation could bring about such an alteration in the ordering, since the inclusion of millions of configurations implies a larger recovery of dynamical correlation. In addition, we have also examined singlet states since Harrison lists them as possible low lying states. The other state is calculated to be close of $16 \mathrm{kcal}^{\mathrm{mol}}{ }^{-1}$ higher than the ground state. The Table 1 shows a list of the spectroscopic constants calculated fitting these results, allowing a comparison with previous works ${ }^{2-6}$. This Table presents a comparison of the calculated fundamental frequency with the experimental spectrum ${ }^{5}$.

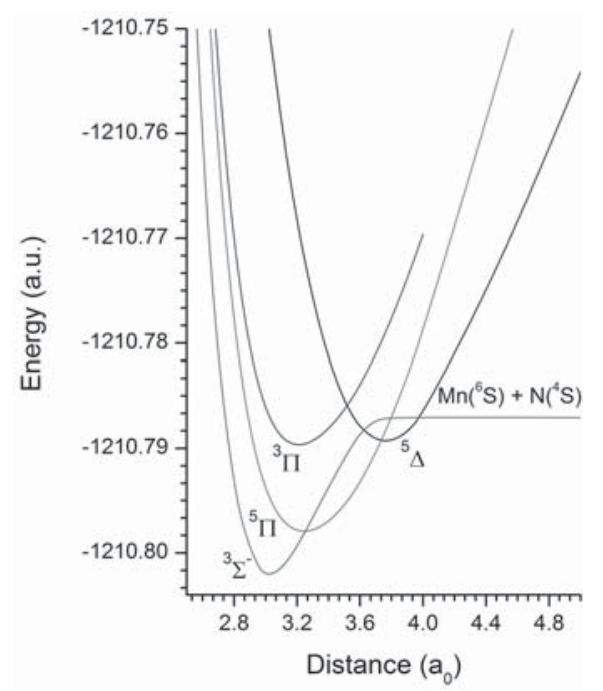

Figure 1. MRSDCI calculated potential energy curves of $\mathrm{MnN}$.

First of all, by inspection it is clear that the observed bands for both isotopes are more closely matched by the ${ }^{3}$
$\Sigma^{-}$state (and not by the quintet, as suggested by Andrews, Bare and Chertihin ${ }^{5}$ ). Accordingly, the calculated equilibrium bond distance for the ${ }^{3} \Sigma^{-}$state is shorter than that of the ${ }^{5} \Pi$ state, what strengthens the choice of the ${ }^{3}$ $\Sigma^{-}$as the most likely ground state. We have observed a number of excited states which are more bound than the lowest states based on the fundamentals frequencies: ${ }^{3} \Delta$ $\left(\omega_{\mathrm{e}}=1031 \mathrm{~cm}^{-1}\right)$ and the ${ }^{1} \Sigma^{-}$states $\left(\omega_{\mathrm{e}}=1029 \mathrm{~cm}^{-1}\right)$. It is noteworthy that our calculated dissociation energies ( 0.69 $\mathrm{eV}$ for the ${ }^{3} \Sigma^{-}$and $2.15 \mathrm{eV}$ for the ${ }^{5} \Pi$ ) are considerably different from the $3.60 \mathrm{eV}$ value suggested by Andrews and coworkers 5 . This cannot be attributed to state mixing, since in DFT calculations the density always collapses to that of the lowest state of the specified multiplicity.

Table 1. Calculated spectroscopic constants of the four lowest lying states of $\mathrm{MnN}$.

\begin{tabular}{|c|c|c|c|c|}
\hline $\begin{array}{c}\text { Properties } \\
\text { /States }\end{array}$ & ${ }^{3} \Sigma^{-}$ & ${ }^{5} \Pi$ & ${ }^{3} \Pi$ & ${ }^{5} \boldsymbol{\Delta}$ \\
\hline $\mathrm{R}_{\mathrm{e}}(\AA)$ & 1.582 & 1.721 & 1.704 & 1.992 \\
\hline & $\begin{array}{c}1.522^{\mathrm{b}}, 1.529^{\mathrm{c}} \\
1.513^{\mathrm{d}}\end{array}$ & $\begin{array}{c}1.636^{\mathrm{b}}, 1.597^{\mathrm{c}}, \\
1.636^{\mathrm{d}}, 1.632^{\mathrm{e}}\end{array}$ & & \\
\hline$\omega_{\mathrm{e}}\left(\mathrm{cm}^{-1}\right)$ & 808 & 548 & 578 & 467 \\
\hline & $\begin{array}{c}916.1^{\mathrm{a}}, 820^{\mathrm{b}}, \\
855^{\mathrm{d}}\end{array}$ & $892^{\mathrm{a}}, 706^{\mathrm{d}}, 704^{\mathrm{e}}$ & & \\
\hline $\mathrm{D}_{\mathrm{e}}(\mathrm{eV})$ & 0.69 & 2.15 & 1.65 & 3.55 \\
\hline & & $2.36^{\mathrm{e}}$ & & \\
\hline $\mathrm{T}_{\mathrm{e}}\left(\mathrm{cm}^{-1}\right)$ & 0.00 & $806,280^{\mathrm{c}}$ & 2662 & 2904 \\
\hline
\end{tabular}

a Exptl., [3]; b Theor., DFT with B3LYP, [3]; c Theor., DFT with BPL, [3] ; d Exptl. and theor., [5]; e Theor., [6].

\section{Concluding Remarks}

We have used CASSCF and MRSDCI calculations to determine the spectroscopic constants of the low lying states of MnN. Our results suggest that the ground state of this species is the ${ }^{3} \Sigma^{-}$, in variance to previous suggestions.

\section{Support}

This work was financially supported by the PIEPI/ IFPR.

\section{References}

1. Merer, A. J.; Ann. Rev. Phys. Chem. 1998, 40, 407.

2. Harrison, J. F.; Chem. Rev. 2000, 100(2), 679. 
3. Miao, M.S.; Lambrecht, W.R.L.; Phys. Rev. B, 2005, 71, 214405.

4. Sahu, B. R.; Kleinman, L.; Phys. Rev. B, 2003, 68, 113101.

5. Andrews, L.; Bare, W. D.; Chertihin, G. V.; J. Phys. Chem. A, 1997, 101, 8417.

6. Wu, Z.; J. Comput. Chem. 2006, 27, 267.

7. Oliveira, M.H.; Martins Filho, H.P.; Da Motta Neto, J.D.; Int. J. Quantum Chem. 2011, 111 (7-8), 1453.

8. Borin, A. C.; Chemical Physics 2001, 274, 99.

9. Wachters, A.J.H.; J. Chem. Phys. 1970, 52(3), 1033.

10. Bauschlicher, C. W.; Langhoff, S.R.; Barnes, R.A.; J. Chem. Phys. 1989, 91, 2399.

11. Wilson, A.K.; Woon, D.E.; Peterson, K.A.; Dunning, Jr., T.H.; J. Chem. Phys. 1999, 110(16), 7667.

12. Woon, D.E; Dunning, Jr, T.H.; J. Chem. Phys. 1993, 98, 1358.

13. Madagan, R.G.A.R.; Scuseria, G.E.; J. Chem. Phys. 1997, 106, 1491.

14. Schmidt, M. W.; Gordon, M. S.; "The Construction and Interpretation of MCSCF wavefunctions", Ann. Rev. Phys. Chem. 1998, 49, 233.

15. Roos, B. O.; "The Multiconfiguration SCF Method", in "Methods in Computational Molecular Physics", edited by Diercksen, G. H. F.; Wilson, S.; Reidel, D.; Publishing, Dordrecht, Netherlands, 1983, pp. 161.

16. Roos, B. O.;"The Multiconfiguration SCF Method", B. O. Roos, in "Lecture Notes in Quantum Chemistry", edited by B.O. Roos, Lecture Notes in Chemistry, Springer-Verlag, Berlin, 1994, 58, 177.

17. Roos, B.O.; Taylor, P.R.; Chem. Phys. 1980, 48(2), 157.

18. Siegbahn, P.E.M.; Almlöf, J.; Heiberg, A.; Roos, B.O.; J. Chem. Phys. 1981, 74, 2384.
19. Yamamoto, N.; Vreven, T.; Robb, M.A.; Frisch, M.J.; Schlegel, H. B.; Chem. Phys. Lett. 1996, 250, 373.

20. Douglas, M.; Kroll, N. M.; Ann. Phys. 1974, 82, 89.

21. Schmidt, M.W.; Baldridge, K. K.; Boatz, J. A.; Jansen, J.; Gordon, M.; GAMESS code.

22. Morse, P.M.; Phys. Rev. 1929, 35, 78.

\section{Marcos H. Oliveira ${ }^{1,2}$, Marcelo André P. Pontes ${ }^{3 *}$, Harley P. M. Filho ${ }^{4}$, Joaquim D. M. Neto ${ }^{4} \&$ Francisco B. C. Machado ${ }^{2}$}

${ }^{1}$ Instituto Federal do Paraná, IFPR, CEP 81530-000, Fone: 55-41-35351809, Curitiba, PR, Brasil

${ }^{2}$ Instituto Tecnológico de Aeronáutica, ITA, CEP 12280-900, São José dos Campos, SP, Brasil

${ }^{3}$ Universidade Tecnológica Federal do Paraná, UTFPR, CEP 81280340, Curitiba, PR, Brasil

${ }^{4}$ Universidade Federal do Paraná, UFPR, CEP 81531-990, Curitiba, PR, Brasil

*e-mail: marceloappontes@gmail.com 